\title{
Die kinderdoop en die verbond by die reformatore Zwingli en Bullinger. 'n Kort oorsig
}

AD PONT

\section{INLEIDENDE OPMERKINGS}

In die raamwerk van hierdie hele ondersoek is die navraag oor die standpunt van Hyldrych Zwingli van Zürich èn sy opvolger Heinrich Bullinger baie beslis ter sake. In die eerste plek omdat Zwingli die eerste van die reformatoriese vadere is wat direk met die Wederdopers gebots het en hy 'n duidelike standpunt teenoor hulle moes inneem. Vanweë die feit dat Zwingli en die Wederdopers bo en behalwe die kinderdoop ook skerp van mekaar verskil het oor die kerkbegrip èn die plek van die kerk in die gemeenskap, het Zwingli 'n verbondsleer ontwikkel. So het daar by hom 'n duidelike skakeling èn verband tussen die kinderdoop èn die verbond na vore gekom.

Bullinger is veral van belang omdat hy die leer van die verbond heelwat verder ontwikkel het en deur die opname van die verbondsleer in die Tweede Switserse Geloofsbelydenis 1560 het dit ook konfessionele status gekry. Die breë aanvaarding wat dié Geloofsbelydenis geniet het, asook Bullinger se invloed in die calvinistiese wêreld, het die verbondsleer veral in die Nederlandse kerklike wêreld veral in die sewentiende eeu ook deur bemiddeling van die Puritanisme, 'n belangrike rol laat speel. Vanweë dié gebeure was dit in die Nederlandse kerklike wêreld, wat vir so 'n groot deel ons teologiese agtergrond bepaal, vanselfsprekend gewees om die kinderdoop en die verbond èn daarmee saam die volkskerk in 'n samehangende verband te sien.

In hierdie uiteensetting was dit nié moontlik gewees om die hele teologiese ontwikkelingslyn wat die kinderdoop, verbond en volkskerk betref, na Nederland deur te trek nie. Hier is net getrag om 'n oomblik te bepaal wat $Z$ wingli en Bullinger se bydrae in hierdie verband was.

\section{ZWINGLI EN DIE KONTROVERS MET DIE DOPERS}

In Zürich, rondom Zwingli, het daar reeds in die jare 1521-1522 kringe ontstaan van lidmate wat hulle met Bybelstudie besig gehou het. 
Onder diegene wat hulle só besig gehou het, was ook mense soos Konrad Grebel, Felix Manz, met wie Zwingli saam Hebreeus geleer het en ook verskillende predikante. Dit was in hierdie kring waar Zwingli self die saak van die kinderdoop ter sprake gebring het, sonder dat dit egter tot duidelike gevolgtrekkings gelei het. In hierdie kringe was dit veral Stumpf, Grebel en Manz wat in 1523-1524 aangedring het op 'n afskeiding van die bestaande kerk om sodoende die stadsraad te dwing om tot ' $n$ hervorming van die kerk oor te gaan. Aangesien Zwingli dié aandrang afgewys het, omdat na sy mening die regte verkondiging die kerk bou en nié afskeiding nie, het daar as gevolg hiervan en ander faktore ' $n$ breuk in die geledere van die hervorming-gesindes in en om Zürich ontstaan. So word dit duidelik dat teenoor Zwingli, wat die kerk wil hervorm, daar 'n groepie is wat voorkeur daaraan verleen om liewer as 'n klein groepie "ware gelowiges" buite die kerk te staan.

Dié groepie radikales het nà kontak met Karlstadt, wat in 1524 in Zürich was, en met Thomas Müntzer, toe hy in die najaar van 1524 in Schaffhausen was, geleidelik al sterker die gedagte van kerklike afskeiding begin huldig. Die ideaal word dan om 'n kerk van ware gelowiges te vestig wat los staan van die owerheid. In hierdie denkpatroon het die kinderdoop ook in die gedrang gekom want in Zürich was, soos elders, die verpligte kinderdoop nie net die waarborg dat almal aan die kerk behoort nie, maar dit het ook die eenheid van die corpus christianum bevestig. Dit is in die Zürichse situasie duidelik dat die kinderdoop bevraagteken is in samehang met die hele verwerping van die corpus christianum-gedagte. Wesenlik het in Zürich die stryd tussen $Z$ wingli en die radikales gegaan om die vraag na die staatsverbonde volkskerk enersyds en die vrye kerk, los van die owerheid, andersyds. In dié kontrovers word die kinderdoop ook betrek omdat dit van owerheidsweë verpligtend gestel is.

$\mathrm{Na}$ 'n dispuut wat op 17 Januarie 1525 in die stadsaal van Zürich gehou is, het die stadsraad op 18 Januarie 1525 andermaal geëis dat àlle kinders binne ag dae na hulle geboorte gedoop moet word. Dit is só gedoen omdat gevoel is, in die raamwerk van die corpus christianumdenke, dat die verwerping van die kinderdoop nie net die eenheid van die kerk verbreek nie, maar ook die eenheid van kerk en owerheid of die burgerlike gemeenskapsorde.

Die antwoord van die radikales was dat hulle op die aand van 18 Januarie 1525 bymekaargekom het. Daar het Konrad Grebel, in die huis van Felix Manz, die voormalige priester Jörg Blaurock gedoop en daarna het Blaurock die aanwesiges gedoop. Dit word normaalweg as 
die begin van die Wederdoperbeweging beskou. Hierdie gemeenskappie het van Zürich uitgewyk na die dorpie Zollikon waar die predikant Brötli 'n Wederdopergemeente opgerig het. Dié eerste poging van die Wederdopers het op sterk teenstand en selfs vervolging deur die owerhede byna skipbreuk gelei. Die Wederdopergemeente moes Zollikon verlaat en vind ' $n$ heenkome by dr Balthasar Humbmaier, ' $n$ voormalige Roomse professor in die teologie aan die Universiteit van Ingolstadt, wat in Waldshut 'n vrye gemeente van Wederdopers opgerig het.

Die afskeiding van die Wederdopers het aanleiding gegee tot ' $n$ hele reeks van geskrifte waarin die onderskeie standpunte gestel is. In vyf geskrifte het Zwingli in die jare 1423-1527 standpunt teen die Wederdopers ingeneem. Dit was sy:

Von gottlicher und menschlicher Gerechtigkeit, 1523,

Wer Ursache gebe zu Aufruhr, 1524,

Von der Taufe, von der Wiedertaufe und von der Kindertaufe, 1525,

Antwort über Balthasar Hubmaiers Taufbüchlein, 1525, en

Widerlegung der Ränke der Wiedertäufer, 1527.

Afgesien van die individuele bydraes wat deur Wederdopers gemaak word in hierdie debat, ontstaan binne die Wederdoper-beweging in 1527 die sg Schleitheimer Artikel wat nie 'n geloofsbelydenis was nie, maar ' $n$ dokument wat die basiese Wederdoper-standpunte saamvat om sodoende ' $n$ sekere mate van eenheid in die beweging te bring.

Vir die doeleindes van hierdie betoog is dit nie noodsaaklik om op Zwingli se hele kontrovers met die Wederdopers in te gaan nie. Tog is dit belangrik om daarop te let dat Zwingli se uiteensetting van wat 'n sakrament is, sy opvattings oor die kinderdoop èn die verbond nié na vore kom in die rustige atmosfeer van die studeerkamer nie, maar in die hitte van 'n stryd wat gedreig het om die hervorming in Zürich en omstreke ernstig te benadeel.

\section{ZWINGLI OOR DIE SAKRAMENT}

As Zwingli se standpunte oor die aard en kwaliteit van die sakrament, die kinderdoop en die verbond nagegaan word in die konteks van sy debat met die Wederdopers, dan word dit gou duidelik dat dit nie àl is wat ter sake is nie. In die debat gaan dit óók oor sonde en genade, en wat geloof beteken. Eintlik word die debat oor die regmatigheid van die kinderdoop die beginpunt van ' $n$ dispuut wat ook handel oor die 
kerkbegrip, die werk van die Heilige Gees, die verhouding van die kerk tot die burgerlike owerheid en gemeenskapsorde en die reg om God volgens eie insigte te dien. Dit is, vir die doeleindes van hierdie betoog, nie moontlik om die hele omvang van die debat weer te gee nie. As daar, vir' $n$ begin gekyk word na Zwingli se argument oor die aard en kwaliteit van die sakrament, dan is dit duidelik dat hy, soos teenoor Rome, die sakrament baie sterk versober. Die sakrament is nié 'n middel waardeur die gelowige genade of vergiffenis van die sonde uit die hande van 'n priester ontvang het nie. Baie skerp wys Zwingli die gedagte af dat die sakrament sèlf iets aan die gelowige kan meedeel, want dit is slegs Christus sèlf wat aan die gelowige die heil kan gee. Die sakrament is dus niks méér as 'n teken nie en kan nie die saak sèlf wees nie. Soos hy dit self stel in sy Von der Taufe, 1525:

"Wir Tütschen wenend, so wir diss Wort Sacrament hörend, es heisse ein Ding, dass uns die Sünd abnemme oder heilig mache, dass aber ein grosser Falsch ist; denn uns Christen mag nüts die Sünd abnemmen oder helig machen denn der einig Christus Jesus, und kein usserlich Ding."

Immers, so betoog Zwingli, die teken en dit waarna dit verwys, kan nooit dieselfde wees nie. Rome het daardie onskriftuurlike kortsluiting gemaak en word daarin deur die Wederdopers nagevolg wat ook leer dat die doop die sonde afwas èn dat die dopeling na die doop sonder sonde is. Dit is ' $n$ verdraaiing van die waarheid.

"Also", sê Zwingli, "ist der Touff ein Zeichen, das (= auf) den Herren Jhesum Christum verpflicht".

Die Wederdopers maak van die doop ' $n$ geloof- en belydenissaak en juis deur dit te doen, verval hulle in ' $n$ nuwe sakramentalisme en wettisisme, wat ook maar ' $n$ vorm van werkheiligheid is. Daardeur toon die Wederdopers dat hulle die evangelie nie reg verstaan het nie. Immers as die mens se verlossing afhanklik gemaak word van die manier en die aard van die doop, dan word die beginsel van solus Christus aangetas.

So kom Zwingli tot die gevolgtrekking dat die doop ' $n$ teken is van 'n bepaalde verpligting teenoor Christus, aanduiding daarvan dat die dopeling die verpligting aanvaar het dat hy 'n Christelike lewe sal lei. Die kinderdoop is dus 'n openbare versekering dat die kind 'n Christelike opvoeding sal ontvang èn 'n inlywingseremonie wat aandui wáár die kind se toekomstige verpligtinge lê. Met ander woorde die doop as sakrament is slegs 'n uiterlike saak. Soos Zwingli dit stel: 
"Also touffend ouch noch hütvytag alle Menschen nit anderst denn usserlich, eintweders dass sy usserlich leerend, oder dass Wasser angiessend oder tunckend."

\section{ZWINGLI OOR DIE KINDERDOOP}

Wanneer Zwingli oor die kinderdoop handel, dan geskied dit teen die agtergrond van die Roomse sakramentsopvatting dat dit die erfsonde en skuld wat elke mens, as nakomeling van Adam, aankleef, afwas. Dié siening het Zwingli teenoor Rome al verwerp met die argument dat Josef van Arimatea, die sterwende moordenaar aan die kruis, Nikodemus, Gamaliël en baie confessores uit die dae van die vervolginge in die Romeinse Ryk nie gedoop was nie. Tog kan aan hulle saligheid nié getwyfel word nie. Die doop is dus vir Zwingli nié voorwaarde vir die saligheid nie. Die doop èn die effektiwiteit daarvan word nié deur die sakrament bepaal nie, maar deur die geloof in Jesus Christus. As die doop, sonder geloof, waardeloos is, dan kom die vraag na die goeie reg van die kinderdoop na vore, want hoe kan 'n pasgebore kind glo?

Hierop gee $Z$ wingli die antwoord dat die uiterlike doop nié reglynig verbind is met die innerlike doop deur die Heilige Gees of wel die geloof nie, want die doop waarmee die kerk doop is die voortsetting van die Johannes-doop wat nié geloof, weergeboorte en die vergiffenis van die sonde veronderstel nie, maar alleen berou. Hier bly Zwingli binne die raamwerk van die reformatoriese teologie wat die verlossing uit die sonde, waarvan die doop 'n teken en 'n seël is, waardeer as iets wat alléén deur God gegee kan word. Die hele gedagte dat daar 'n voorwaarde vir die doop is, soos die Anabaptisme wil, wat prediking, berou en geloof as absolute voorwaardes vir die doop poneer, is ' $n$ afwyking van die soli Deo gloria van die reformatoriese teologie.

Hierby voeg $Z$ wingli die argument van uitverkiesing en stel dat sommige tot die lewe uitverkies is. Aangesien 'n mens nie by kinders kan vasstel wie uitverkies is nie, moet alle kinders van Christelike ouers gedoop word.

Dié argument was egter nié voldoende nie, omdat Zwingli se teenstanders geëis het dat hy met NT-gegewens die regmatigheid van die kinderdoop sal aantoon. In hierdie deel van die debat het die Wederdopers as konsekwente biblisiste op hierdie punt Zwingli nogal heelwat probleme besorg. Zwingli se argument hier, kort saamgevat, is dat hy allereers stel dat die kinderdoop in die NT nòg gebied nòg verbied word. Dan voer hy vir die goeie reg van die kinderdoop die volgende argumente aan, naamlik dat dit nie in die NT verbied word nie; dat op 
die doop van Johannes die koms van Christus gevolg het. Aangesien by Johannes doop en onderwysing saamgaan, gebeur dit vandag nog net so in die kerk en daarop volg die genadegawe van die geloof of wel die bekering en weergeboorte. Verder beroep Zwingli hom op die "oikos-tekste" en argumenteer dat dit die kinderdoop van die begin af veronderstel het. Hier verwys hy veral na $H$ and 16:15 en ook na 1 Kor $1: 16 ; 10: 2$ en 16:15. Die algemene doopbevel, Matt 28:19, interpreteer Zwingli ook as 'n opdrag om kinders te doop, omdat dit nêrens verbied word nie. Verder argumenteer hy dat as die NT slegs stel dat volwassenes gedoop is, beteken dit nie noodwendig dat hulle nié kinders gedoop het nie. Sola scriptura, so sê Zwingli, beteken nie dat letterlik àlles neergeskryf is nie. Baie is klaarblyklik nie neergeskryf nie. So word daar nêrens uitdruklik gesê dat Maria, die moeder van Jesus, of die apostels gedoop is nie. Daarom kan enige predikant redelike of klaarblyklike argumente uit die Skrif aflei. Die Wederdopers wat net met 'n direkte Skrifwoord tevrede gestel wil word, wil met dié houding hulleself bo die Skrif verhef en 'n billike uitleg van die Skrif, wat hulle nie pas nie, verhinder. Daarby stel Zwingli dat die OT woord vir ouers altyd óók die kinders ingesluit het. Verder beroep Zwingli hom óók op die argument dat die dispuut onder die apostels oor die afskaffing van die besnydenis, beteken dat hulle kinders gedoop het soos Origines en Augustinus ook bevestig het. Zwingli argumenteer verder dat waar die NT géén duidelike aanduidings gee nie, die OT geraadpleeg kan word waar die analogie duidelik is. Dit doen Zwingli veral omdat die analogie besnydenis en kinderdoop vir hom vasstaan. Zwingli het met 'n beroep op Rom 4:1, 1 Kor 10 en Kol 2:11 gestel dat die doop in die plek van die besnydenis gekom het en dat die kinders as verbondskinders gedoop moet word. Die kinderdoop is vir Zwingli 'n teken van die hernuwing vir alle mense van God se verbond met Abraham en daarom is die doop nie net die teken van die toelating tot die Christelike geloofsgemeenskap nie, maar ook tot burgerskap in die burgerlike gemeenskapsorde. Daarom plaas die doop 'n besondere verpligting op die ouers, die doopgetuies en die dopeling. So gesien is die doop 'n Pflichtzeichen. Op grond van dié argumente formuleer Zwingli die volgende samevattende stellings:

"So er (di die doop) num nit abweschen mag und aber von Gott ist yngesetzt, so muss er ie (= jedenfalls) ein Pflichtzeichen sin des Volcks Gottes und sust nütz anders. 
Der Christen Kinder sind nütz minder Gottes Kinder weder ire Eltren, glych als wol als im alten Testament. So sy nun Gottes sind, wer wil inen vor dem Wassertouff sin?

Die Bschnydung ist den Alten gewesen des Zeichens halb, das uns der Touff ist. Wie nun die den Kinden geben ist, also sol ouch der Touff den Kinden geben werden."

\section{ZWINGLI OOR DIE VERBOND}

Met Zwingli se sterk beklemtoning van die eenheid van die OT en NT èn die eenheid van die genadeverbond, lê Zwingli nie net die eerste grondslae van 'n verbondsteologie nie, maar beklemtoon hy ook die feit dat die Wederdopers die OT grotendeels verwerp het as Heilige Skrif. Met die beklemtoning van die verbond as grond vir die kinderdoop, na analogie van die besnydenis, kan Zwingli ook die staatsverbonde volkskerk verdedig en verwerp hy die Wederdopers wat hulle afskei om 'n vrye kerk van ware gelowiges te vorm. Daarby verwerp hy vanuit die verbond die Wederdopers se verwerping van elke vorm van deelneem aan staats- of militêre diens en hulle pseudo-Bybelse kommunisme. Teenoor hierdie opvattings van die Wederdopers en hulle eis van bekering en goeie werke, stel Zwingli die leer van die uitverkiesing om sodoende die objektiwiteit van die heil, wat nooit subjektief veranker kan wees nie, te beklemtoon.

Aangesien Zwingli slegs 'n verbondsteologie suggereer maar nie uitwerk nie, is dit miskien geleë om ook aandag aan Heinrich Bullinger se opvattings in hierdie verband te gee, aangesien Bullinger 'n volledige verbondsteologie ontwikkel het.

\section{HEINRICH BULLINGER OOR DIE VERBOND}

Heinrich Bullinger, die opvolger van Zwingli het gedurende die vyfen-veertig jaar wat hy aan die hoof van die Zürichse kerk gestaan het, 'n groot en weldadige invloed in die reformatoriese kerke uitgeoefen. Bullinger het teologies gesproke 'n eie weg gegaan en daar is duidelike verskille aan te toon tussen Bullinger se teologie en dié van Calvyn en die Calviniste, die Lutherane en die Anabaptiste. Die duidelikste blyk dit uit sy verbondsteologie en sy siening van die Christelike gemeenskap, gebaseer op sy verstaan van die verbond.

Die begrip verbond, so wys Wayne Baker uit, is vryelik deur die reformatoriese vadere, ook Luther en Calvyn gebruik. Dié begrip is gewoonlik idiomaties gebruik, net soos die begrip uitverkiesing om die sola fide en sola gratia beginsels van die hervormde teologie te verwoord. Bullinger het egter 'n ander opvatting van die verbond wat 
vir hom 'n gemeenskaplike of bilaterale verbond tussen God en mens was, terwyl Luther en Calvyn dit weer verstaan as 'n testament-verhouding. Die begrip testamentum het ' $n$ dubbele betekenis naamlik as verwysing na die OT en NT in hermeneutiese sin, maar dan ook as testament-van-God wat die soteriologiese belofte bevat. Normaalweg het die reformatoriese teoloë die begrip verbond in sy testament-betekenis gebruik waar Christus sowel die opsteller van die testament as die beloofde erfenis is en waar die uitverkorenes of gelowiges die erfgename is. Bullinger daarenteen gebruik die begrip verbond as 'n ooreenkoms tussen God en mens wat nie alleen God se beloftes bevat nie, maar ook bepaalde voorwaardes of eise waaraan die mens moet voldoen.

Dié bilaterale of voorwaardelike verbond het die gevaar dat dit die moontlikheid bevat om die sentrale reformatoriese leer van regverdiging deur die geloof alleen deur die genade alleen, te verswak. Daarom het Calvyn eerder van ' $n$ testament gepraat binne die raamwerk van 'n duidelike uitverkiesingsleer wat dus nie die leer van die regverdiging deur die geloof alleen kan verswak nie. Vir Calvyn het die uitverkiesingsleer saamgeval met die sola fide en die sola gratia en dit beskerm.

Bullinger het egter aan die voorwaardelike verbond vasgehou, al veroorsaak dit 'n sekere spanning ten opsigte van die sola gratia. Vir Bullinger is die verbond die grondliggende struktuur waarbinne God in die geskiedenis by en met die mens betrokke is. So kom Bullinger daartoe om sowel 'n bilaterale verbond tussen God èn mens te leer as 'n sola gratia wat hy verskans in 'n duidelike uitverkiesingsleer. Sodoende interpreteer Bullinger sowel die sola fide as die sola gratia binne die omvattende struktuur van die verbond, sonder om terselfdertyd in 'n Pelagiaanse slagyster te trap. In Bullinger se geskrif Von der Touff korreleer hy die kinderdoop met sy verbondsopvatting. Hier stel hy dat die verbond wat God gee, veral by Abraham direk en duidelik word. God beloof aan Abraham sy seën (Gen 12,15,17) en in antwoord daarop sal Abraham naby God en opreg lewe (Gen 17:1). Dié verbond, stel Bullinger, is ' $n$ ewige verbond. Dié verbond word vervul in die dae van Johannes die Doper, want sy taak was om die volk voor te berei vir die koms van die Messias wat onder die verbond belowe was. Johannes doop en dit is ' $n$ teken waarmee hy diegene geteken het wat hulle sou bekeer en Christus as Messias sou aanvaar.

So vervang die doop die besnydenis want die bloed van die besnydenis, ' $n$ teken van die bloed van Christus, is vervul. Christus herbevestig 
die Goddelike verbond met sy bloed. In die raamwerk van die verbond vervang die doop nou, in die nuwe bedeling, die besnydenis. Sodoende is die doop 'n teken wat aan die volk van God gegee word en dit verbind die gelowiges aan Christus en verplig hulle tot ' $\mathrm{n}$ lewe aan God toegewy. Tweedens hou die doop die gelowiges binne die verbond en in 'n lewe wat God welgevallig is.

Só beklemtoon Bullinger nie alleen die verbondsplig van die gelowige nie, maar ook die essensiële eenheid van die verbond. Daarom het die apostels met dieselfde doop as Johannes gedoop en het hulle dieselfde verbond verkondig. Petrus stel, volgens Bullinger, dat die Abrahamverbond na Christus voortduur (Hand 3:24) en hy doop die heidene met dieselfde doop as dié van Johannes (Hand 10:44-11:18). Net so het Paulus ook die Johannesdoop gelykgestel met die doop van Christus (Hand 19:1).

In sy De testamento van 1534 het Bullinger sy uitgewerkte leer van die verbond gegee. Die duidelikste uiteensetting van Bullinger se siening van die samehang tussen doop, kinderdoop en die verbond word egter gevind in die Tweede Switserse Geloofsbelydenis van 1560. Die feit dat dié Geloofsbelydenis so 'n wye aanvaarding in die Calvinistiese kerke gevind het, toon aan hoe breed Bullinger se invloed was. Omdat die samehang kinderdoop en verbond vir die doeleindes van hierdie uiteensetting belangrik is, moet dié aspek uit die Geloofsbelydenis 'n oomblik bespreek word.

\section{BULLINGER OOR DIE DOOP EN DIE VERBOND}

Die doop is ' $n$ toetrede-sakrament in die kerk en diegene wat so opgeneem word is die uitverkorenes wat reeds in die verbond met God opgeneem is. Die doop self is en bly by Bullinger ' $n$ teken en nie die saak self nie (Confessio Helvetica posterior, cap. 19). Die doop is dus 'n teken van die opname in die familie van die erfgename van God en dit gee aan die dopeling die titel van kind van God.

Vanuit hierdie uitgangspunt word die kinderdoop geregverdig. Want volgens Mark 10:14 behoort die koninkryk van God "juis aan mense soos hulle" en dáárom kan en moet die kinders van gelowiges gedoop word. Die kinders is in die verbond opgeneem en daarom mag hulle die teken van die verbond ontvang. Hier gebruik Bullinger die argument dat die kinders onder die ou verbond besny is en volgens $\mathrm{Kol}$ 2:11 is die doop die Christelike besnydenis. Daarby is die deurtog deur die Rooi See vir Paulus ' $n$ heenwysing na die doop en daar was tog ook 
kinders by gewees. Al is dit so dat Christus nêrens uitdruklik opdrag gee om kinders te doop nie, moet hulle tog gedoop word. Dan stel Bullinger, net soos Zwingli, dat nêrens gesê word dat ook vroue die nagmaal mag ontvang nie en tog is dit vanselfsprekend.

Dan verwys Bullinger ook na die oikos-tekste en verwerp op grond van Mark 1:4 die Wederdopers se argument dat skriftuurlik geëis word dat onderrig en belydenis van geloof aan die doop vooráf moet gaan. Volgens Bullinger maak die Wederdopers die bediening van doop afhanklik van die mens, terwyl die doop juis teken is van die verbond van die genade en barmhartigheid van God. Die fout hang saam met die Wederdopers se verwerping van die eenheid van die verbond. Daarom stel hy ook dat die Wederdopers die doop verdraai. God het dit ingestel as 'n teken van toetrede vir almal wat deel van die verbond is. Die Wederdopers maak die doop egter 'n teken van hulle afgeskeie groep en van hulle eie gewaande heiligheid.

Hoewel hierdie paar opmerkings oor Bullinger se opvattings van die verbond nie naastenby volledig is nie, want vanuit die verbond gee Bullinger aanwysings vir die totale Christelike gemeenskap èn sy owerheid, is dit vir die bespreking van die kinderdoop in die Zürichse reformatoriese tradisie nié van direkte belang nie. Dit is egter wel duidelik dat Bullinger, vanuit en vanweë sy verbondsteologie, ánders oor die uitverkiesing, erfsonde èn verlossing dink as Calvyn, omdat Calvyn ' $n$ ander verbondsopvatting het.

\section{SLOTOPMERKING}

Wanneer Zwingli en Bullinger se leer in verband met die kinderdoop nagegaan word, dan kom die verbondsteologie van die Zürichse reformatore sterk op die voorgrond, en dit verteenwoordig ' $n$ ander tradisie as die Calvinistiese. Tog het dié tradisie ' $n$ belangrikheid vir die gesprek oor doop en verbond wat dikwels onderskat word, en dit is alleen gedurende die laaste dekade of wat dat Bullinger weer aandag gekry het. By die bestudering van Bullinger se werk word dit duidelik dat sy teologie ook van belang is, al is dit so dat sy siening van die Christelike volk waarin die burgerlike owerheid so 'n groot rol speel, sy hermeneutiese beginsels vir die uitleg van die Skrif en sy kerkopvatting vir ons wat in die Calvinistiese teologiese tradisie staan, enigsins vreemd in die ore klink. Tog bly dit 'n vraag of Bullinger se grondliggende argument dat die verbond van God met sy volk die basiese struktuur van die verhouding God en mens is, nie tog die oorsaak was dat 
veral in die sewentiende-eeuse verbondsteologie, die saak grotendeels op 'n syspoor geraak het nie.

\section{Bibliografie}

Die volgende geskrifte is, sonder nadere verwysing, gebruik by die skrywe van hierdie uiteenselting.

BARTH, GERHARD 1981. Die Taufe in frühchristlicher Zeit. Neukirchen-Vluyn: Neukirchener Verlag.

GÄBLER, U und E HERKENRATH 1975. Heinrich Bullinger Bd 1. Zürich: Theologischer Verlag.

KARLBERG, MW 1980-1981. Reformed Interpretation of the Mosaic Covenant, The Westminster Theological Journal. 43, 1-57.

KOCH, E 1968. Die Theologie der Confessio Helvetica Posterior. Neukirchen-Vluyn: Neukirchener Verlag.

LOCHER, GOTTFRIED W 1979. Die Zwinglische Reformation. Göttingen: Vandenhoeck u Ruprecht.

PAYTON JR, JAMES R 1979-1980. Infant Baptism and the Covenant of Grace. The Westminster Theological Journal. 42, 406-419.

PFISTER, R 1948. Zwingli Hauptschriften. Zürich: Zwingli Verlag.

POTTER, GR 1976. Zwingli. Cambridge: Cambridge University Press.

SCHMIDT-CLAUSING, F 1965. Zwingli. Berlin: Walter de Gruyter.

WAYNE BAKER, J 1980. Heinrich Bullinger and the Covenant. Athens: Ohio University Press.

WALSER, PETER 1957. Die Prädestination bei Heinrich Bullinger im Zusammenhang mit seiner Gotteslehre. Zürich: Zwingli Verlag.

WINDHORST, C 1976. Täuferisches Taufverständnis. Leiden: EJ Brill.

YODER, JOHN H 1968. Täufertum und Reformation im Gespräch. Zürich: EVZ-Verlag. 